\title{
Biases in RCS tree ring chronologies due to sampling heights of trees
}

\author{
Julia Autin ${ }^{1,4}$, Fabio Gennaretti ${ }^{1,2,4}$, Dominique Arseneault ${ }^{1, *}$, Yves Bégin ${ }^{3}$
}

1: Département de biologie, chimie et géographie et Centre d'études nordiques, Université du Québec à Rimouski, 300 Allée des ursulines, Rimouski Qc., Canada, G5L 3A1

2: Present addresses: Consortium Ouranos, 550 Sherbrooke Ouest, Montréal, Qc., Canada, H3A1B9 and CEREGE, Europôle Méditerranéen de 1'Arbois, Avenue Louis Philibert, BP 80, 13545 Aix-en-Provence cedex 04, France.

3: Institut National de la Recherche Scientifique, 490 de la Couronne, Québec, Qc., Canada, G1K 9A9

4: Julia Autin and Fabio Gennaretti contributed equally to this work

*: Corresponding author: dominique_arseneault@uqar.ca 
Abstract: The Regional Curve Standardization (RCS) is one of the most employed standardization methods to remove biological signals in long tree ring chronologies. The approach assumes that an overall age-related growth trend typify all tree ring series to be included in a standardized tree ring chronology. Although several potential problems of the method have been examined, the influence of varying the sampling height along tree stems has not been evaluated. Considering that age-related growth trends may vary with stem height, biases may arise when combining samples from unknown or variable sampling heights, a frequent situation with subfossil logs. In this study we perform a detailed stem analysis of 15 lakeshore black spruce (Picea mariana Mill. B.S.P.) trees in the taiga of eastern Canada to describe how the age-related growth trend varies with stem height and evaluate associated biases in RCS chronologies built from living and subfossil trees. Results show that the age-related growth trends vary markedly and systematically along stems, potentially generating large methodological biases in RCS chronologies, especially near the recent chronology end. These biases may lead to erroneous reconstructions of recent climatic trends and cause false divergence between tree ring and climate series. We have developed a correction procedure that appears efficient in removing these biases from chronologies built with the lakeshore trees and associated subfossil logs.

Keywords: dendrochronology, paleoclimatology, tree ring chronology, subfossil tree, living tree, sampling height, methodological bias, boreal forest, Picea mariana, RCS standardization. 


\section{Introduction}

Among proxy records used to reconstruct the climate of the last millennia, tree ring chronologies have a dominant role (PAGES 2k Consortium, 2013). Trees in the middle and high latitudes are common, long-living, and sensitive to climate, with their rings being annually resolved and easily datable, (Fritts, 1976). Long tree ring chronologies are often composed of hundreds of crossdated individual tree ring series belonging to living and dead (subfossil or historic remains) trees (Eronen et al., 2002; Grudd et al., 2002; Gunnarson and Linderholm, 2002; Friedrich et al., 2004; Cook et al., 2006; Shao et al., 2009; Gennaretti et al., 2014c). In general, for tree rings to be used as climate proxy, all individual tree ring width series must be standardized to remove the influence of biological signals (i.e., rings are larger in youth than in old age).

The Regional Curve Standardization (RCS) is one of the most commonly used standardization methods (e.g. Büntgen et al., 2011; Stambaugh et al., 2011; McCarroll et al., 2013; Gennaretti et al., 2014c), because its design allows the preservation of low-frequencies, even when short-lived trees are used (Briffa et al., 1992; Cook et al., 1995; Esper et al., 2003; Peters et al., 2015). This method relies on the computation of a mean age-related growth curve by averaging all available tree ring width measurement series according to their pith age. The average growth curve, which represents the mean biological signal of the corresponding collection of samples, is then used to standardize each individual tree ring series by division or subtraction. The standardized individual tree ring indices are finally realigned according to the calendar year and averaged to obtain a RCS chronology. 
The RCS method requires high replication of trees belonging to a homogeneous population not disturbed by external non-climatic factors (Esper et al., 2003, Björklund et al. 2013), which are difficult conditions to meet. Furthermore, additional problems can affect the results, including (1) a changing sample age structure through time may create some distortion in standardized growth indices when the age-related growth model does not fit all cambial ages, especially in the most recent parts of tree ring chronologies where the mean cambial age of tree rings generally increase (Esper et al., 2008; Linderholm et al., 2010); (2) if samples are not evenly distributed over time or represent a limited time period some of the variance due to climate forcing on tree growth may be removed during the standardization procedure, leading to a "trend distortion" in resulting index series (Melvin and Briffa, 2008; Briffa and Melvin, 2011); and (3) living and dead trees do not always belong to a homogeneous population, thus requiring the two subsets to be processed separately (Büntgen et al., 2005, 2011; Stambaugh et al., 2011).

Another potential source of bias in RCS chronologies may be related to sampling heights on trees, especially in chronologies composed of living and subfossil trees. Living trees are often sampled near the trunk base in order to maximize the number of rings, while dead trees are sampled at varying, often unknown heights according to decay conditions. In cases where the growth curve vary with tree height (Clyde and Titus, 1987; Alteyrac et al., 2005), these inconstant sampling heights could possibly introduce bias into standardized chronologies, because the age-growth relationship is assumed to be constant among all processed samples when using the RCS method.

The main goal of this study is to show how growth patterns of living trees may vary according to sampling heights and to verify if this aspect may introduce biases in climate reconstructions constructed from long, RCS-standardized tree-ring series. To achieve this 
objective, we first performed a detailed analysis of tree ring growth patterns according to sampling height in 15 lakeshore living trees collected at three sites in the taiga of Quebec (Fig. 1). These sites are part of a network previously used to develop millennial-long tree ring chronologies combining lakeshore living trees and subfossil trees preserved in adjacent lake littoral zones (Gennaretti et al., 2014a). Subsequently, we used the ring-width series from the 15 living trees in simulation and real data experiments to show how different growth patterns according to sampling height may introduce important biases in RCS chronologies. Finally, we propose a correction procedure to attenuate these biases. For clarity, Table 1 describes some technical terms and abbreviations that are used throughout the paper as well as the algorithm used to obtain all the smoothed growth curves.

\section{Studied sites and trees}

Three lakes were investigated (L1, L12 and L20). Around each lake, riparian forests are characterized by old-growth black spruce (Picea mariana [Mill.] B.S.P.) stands growing on glacial deposits with an abrupt lakeshore bank sheltered from dominant winds (Fig. 1). We sampled 15 living trees in the lakeshore forests (5 black spruce per site; sampling year: 2010). The living trees were selected among the dominant trees growing near the lakeshore (Fig. 1) because they would be the most likely to generate subfossil stems similar to those already used to develop millennial-long tree ring chronologies at the same sites (Gennaretti et al., 2014c). A stem cross section was taken each $40 \mathrm{~cm}$ on each living tree from the base to the top for stem diameters greater than $3 \mathrm{~cm}$. In total, 338 cross sections were sampled and the height of the collected uppermost sections varied between $440 \mathrm{~cm}$ and $1080 \mathrm{~cm}$ depending on the trees (Supplementary Table 1). In the laboratory, tree ring widths were measured with a precision of $1 / 100 \mathrm{~mm}$ along 
two radii per cross section, which were selected to avoid reaction wood and separated by an angle greater than $90^{\circ}$. Potential errors in measurements were detected by crossdating each radius with the local master chronology using standard dendrochronological procedures as described by Arseneault et al. (2013). Finally, the two radii of each cross section were averaged to obtain a mean growth curve per sampling height per tree. Six out of the 338 individual series were excluded because cross sections had missing pith and unknown pith offset. Only calendar years or cambial ages with sample replication of at least 3 have been considered in all analysis. In a previous study at the same sites, 991 subfossil trees were sampled in the littoral zone of the lakes (190 at L1, 220 at L12, and 581 at L20) and were crossdated over the last 1400 years to produce three local, millennial-long tree ring chronologies (Gennaretti et al., 2014c). Here we used these 991 individuals to determine the overall growth curve of the subfossil trees and to test an RCS correction method.

\section{Growth of living and subfossil trees}

To characterize the radial and longitudinal (i.e., along the stem) growth patterns of a typical tree of the studied lakeshore forests, we mapped ring width according to cambial age and sampling height by averaging the 15 living trees from the three sites (Fig. 2a and Supplementary Fig. 1). This cartography is justified by the fact that the radial and longitudinal growth patterns of living trees are reasonably similar among sites. Indeed, we checked for significant differences using Kruskal-Wallis one-way analysis of variance tests (Fig. 2b). The results indicate that only $16 \%$ of the pixels in Fig. $2 b$, each representing a specific cambial age at a specific sampling height, show significant differences in ring width distribution from at least one site $(\mathrm{p}<0.1)$. 
Although we measured only 15 series per sampling height, these data are sufficient to show systematic changes of the age-related growth pattern along stems. Growth curves differ markedly between the basal 2 meters of the stems and the stems sections above 2 meters (Fig. 2a). Below 2 meters, tree ring widths increase progressively with cambial age, reach their maximal values around cambial age 100-150, and then subsequently decrease. Slow growth below the height of 2 $\mathrm{m}$ during the first 100 years can be explained by the ecology of these forests, which are oldgrowth stands established after fire more than 350 years ago (Gennaretti et al., 2014b). Dominant trees composing the present-day forests most likely established as layers (i.e., new individuals formed from another tree through the rooting of its lower branches that are touching the ground). Indeed, black spruce rarely live more than 250-300 years and often regenerates from layers. Therefore, suppressed juvenile growth at low sampling heights probably corresponds to the progressive differentiation of basal branches towards independent trees (Rossi et al., 2009). Rapid juvenile growth occurs only at higher sampling heights $(>200 \mathrm{~cm})$, corresponding to the growth of well-established individual stems. Above two meters, ring width progressively decreases with cambial age according the typical pattern documented for several conifers species (Rossi et al., 2008). However, the decreasing rate of the growth curve systematically accelerates with sampling height. Although poorly documented, this longitudinal trend may reflect faster senescence and changing foliage density with increasing height, as well as increasing physiological limitations with increasing tree size (Alteyrac et al., 2005, 2006; Park et al., 2009).

Subsequently, we compared the growth patterns of living and subfossil trees to verify if we could determine which heights the subfossil cross sections correspond to. First, a series of Wilcoxon rank-sum tests shows that significant differences between growth patterns of subfossil and living 
trees are attenuated when living trees are sampled at $440 \mathrm{~cm}$ above the ground (Fig. 2c). Second, when all sampling heights on living trees are mixed, the mean growth curve becomes even more similar to the one calculated from subfossil stems (Fig. 3). According to Wilcoxon rank-sum tests, $30 \%$ of the cambial ages significantly differ in ring width between subfossil and living trees at $440 \mathrm{~cm}$, compared to only 19\% when all sampling heights are mixed (Fig. 3a). Consequently, these results suggest that the cross sections collected on the subfossil stems correspond to a more or less random sampling around the height of $440 \mathrm{~cm}$. Previous work has shown that less than $5 \%$ of subfossil individuals comprise a root system (Gennaretti et al., 2014a), indicating that stumps of corresponding trees remained attached to the shore after partial uprooting. Accordingly, the reduced occurrence of basal and upper stem parts as compared to mid-stem parts (i.e. $440 \mathrm{~cm}$ ) among the subfossil samples may have resulted from an accentuated erosion of stem bases by ice and waves at the shoreline, combined with our systematic sampling of subfossil stems at their maximum diameter away from the upper ends.

\section{Common signals and biases in RCS chronologies}

Even if the growth curves vary according to stem height, a homogeneous ring width signal is superimposed on this varying trend. Standardizing the ring width series from each sampling height using the RCS approach and the corresponding height-specific growth curve (Fig. 4a) gives very similar series of growth indices among sampling heights for the living trees (Fig. 5). However, because subfossil samples originate from unknown and variable heights they should not be standardized with a typical RCS approach (i.e., dividing each series by the mean growth curve of all series). Indeed, the growth curves are height-specific (Fig. 4a). Considering that our dataset is strongly dominated by subfossil stems, the growth curve of all samples (living plus 
subfossils) would be nearly similar to the subfossil one. Consequently the average biases introduced in a typical RCS chronology by an individual ring width series sampled at a specific height can be estimated by dividing each height-specific growth curve for living trees by the mean curve constructed from all subfossils (Fig. 4a, b). The resulting height-specific, age-related average bias curves indicate that bias amplitude would be greatest in samples from the most extreme stem heights (i.e., below $120 \mathrm{~cm}$ and above $920 \mathrm{~cm}$ ). At stem base, large positive biases would occur towards the mid-series. Conversely, at higher stem heights, large negative biases would occur at series ends. These biases due to sampling heights are substantial. For example, the smoothed RCS chronologies of L1, L12, and L20 vary between 0.68 and 1.77 over the last 1100 years, (Gennaretti et al. 2014c), whereas biases introduced by an average living tree sampled at the trunk base would vary between 0.15 and 2.75 (Fig. 4b).

In theory, if subfossil logs are well-replicated and sampling heights are uniformly mixed over the entire time period covered by an RCS chronology, then these positive and negative biases should cancel out among samples, except during time periods of changing age structure. This should particularly occur towards the chronology end where all living trees are re-aligned by their final years, which tend to be negatively biased (Fig. 4c). To verify this hypothesis, we simulated the development of a long RCS chronology over a 1000 years period. In order to mimic a dataset that can be assembled from large stocks of lake subfossils in the Québec taiga, 200 hypothetical successive subfossil stems were systematically lagged by 5 years from their last year, for simulation years 0 to 1000 (Supplementary Fig. 2). We assumed that each subfossil individual corresponds to a stem height selected at random between 80 and $880 \mathrm{~cm}$. To analyze the impact of a varying age structure on biases generated by the RCS method, we also doubled 
the recruitment rate of subfossil stems for simulation years 400 to 500 , thus disturbing the mean cambial age over simulation years 200-500, given that these supplementary stems contained 101211 tree rings (Supplementary Fig. 2). To construct the recent end of the chronology, we simulated the sampling of 25 living trees and considered two scenarios. In the "S1_H80" scenario (Table 1), all living trees were sampled at $80 \mathrm{~cm}$ in order to mimic a standard sampling where the investigator wants to maximize the length of the series. In contrast, the "S1_H400" scenario mimics the sampling of living trees at $400 \mathrm{~cm}$. Although a smallest difference with the growth curve of subfossil stems occurs when living trees are sampled at $440 \mathrm{~cm}$ (Figs. 2c and 4), we retained the height of $400 \mathrm{~cm}$ to allow comparisons with the work of Gennaretti et al. (2014c), which is based on living trees sampled at $400 \mathrm{~cm}$. In both scenarios the lengths of the series of living trees were selected to reproduce real conditions. For the S1_H80 scenario the lengths of the series of living trees were selected randomly (with replacement) among the 15 trees sampled at $80 \mathrm{~cm}$ in this study. For the S1_H400 scenario, we reproduced the lengths of the 25 series sampled at $400 \mathrm{~cm}$ at L20 by Gennaretti et al (2014c). In both scenarios the resulting living trees are relatively uneven-aged due to the old-growth nature of the sampled forests. For each scenario, we summed up the biases generated by the RCS standardization of each samples available each year, given the corresponding sampling height (Fig. 4b).

The results confirm that biases generated by the RCS standardization of samples from varying sampling heights nearly cancel out among individual samples (Fig. 6e). The remaining noise reflects variations in the age structure of subfossil stems (as reflected in the mean cambial age), especially at the recent end of the chronology that remains strongly biased (Fig. 6e). Mixing living trees sampled at $80 \mathrm{~cm}$ with subfossil specimens from varying heights would 
systematically and strongly overestimate the early $20^{\text {th }}$ century warming trend. Conversely, sampling living trees at $400 \mathrm{~cm}$ would strongly underestimate the recent warming trend (Fig 6e). Both scenarios would result in an apparent negative divergence of tree growth relative to climate trends, especially during the last 40 years.

Various climatic factors such as moisture stress or complex non-linear or threshold climategrowth relationships have already been reported to cause anomalous low growth over recent portions of tree ring chronologies (Büntgen et al., 2006; D'Arrigo et al., 2008; Porter \& Pisarik, 2011; Girardin et al., 2014). This divergence phenomenon has become an important issue in dendroclimatological studies because it may indicate decreasing forest productivity and a different sensitivity of tree ring series to climate variables during the recent decades, which are generally used to calibrate climatic reconstructions. Our results suggest that RCS chronologies are also likely to contain a strong divergence signal of methodological origin when sampling heights on trunks are variable and not taken into consideration.

We examined more precisely how these biases due to variable sampling height would propagate in RCS growth indices computed from actual living trees at our three sites. Here, we considered three sampling height scenarios (Table 1). Similar to the millennial simulation above, the first sampling scenario (hereafter "S2_H80") is based on the 15 samples collected at $80 \mathrm{~cm}$ on living trees, whereas the "S2_H440" scenario is based on the 15 samples taken at $440 \mathrm{~cm}$. The third scenario (S2_Hmix) is based on all samples $(\mathrm{n}=332)$ representing the various sampling heights (from 0 to $1080 \mathrm{~cm}$ ) in the 15 living trees. This latter data subset was designed as a possible approach to attenuate the biases in the final RCS chronology as our results show that the 
growth curve of subfossil trees is very similar to the curve of living trees when all sampling heights are mixed (Fig. 3). Each of the three sampling scenarios was processed using three variants of the RCS method (Table 1). In the first RCS variant ("HSpecific_RCS"), all individual series were standardized by dividing them with the growth curve from all living trees sampled at the corresponding height of the sample subset (either $80 \mathrm{~cm}, 440 \mathrm{~cm}$, or all samples from all heights). The second variant (hereafter "HSpecific_SF-RCS") is a signal free RCS chronology (Melvin \& Briffa 2008). The signal free approach was introduced in dendroclimatology to remove "trend distortion" in resultant chronologies (i.e., when the standardization leads to an unwanted distortion of the signal due to a common climate forcing). Here, we used the standard options of the software CRUST to calculate this approach (Melvin \& Briffa 2014). In the third variant ("Sufossil_RCS"), each living series was standardized by dividing it with the growth curve of all subfossil trees (991 trees sampled at the three sites). This represents the case situation where numerous subfossil samples and few living trees are combined to produce a long RCS chronology.

Many important results can be deduced from this analysis (Fig. 7). The subsets S2_H80 and S2_H440 produce similar chronologies when the HSpecific_RCS and HSpecific_SF-RCS variants are used. Because these chronologies are standardized in a height-specific manner, they are free from height-related bias (Fig 5) and show the actual common (climate) forcing on tree growth. The fact that HSpecific_RCS produces similar results as its HSpecific_SF-RCS equivalent means that trend distortion, as defined by Melvin et al. (2008), is not an important issue here. This situation was also observed with similar material from the Fennoscandian boreal forest (Esper et al., 2014) and probably reflects the homogeneous distribution of our samples in 
time as well as their high replication (Gennaretti et al., 2014a). Comparing these unbiased chronologies with the variant Subfossil_RCS reveals the bias attributable to sampling height that would emerge when using the typical RCS approach with a subfossil-dominated dataset. The Subfossil_RCS variant combined with the subset S2_H80 scenario is well above the other curves because the growth curve of living trees sampled at $80 \mathrm{~cm}$ is much above the growth curve of all subfossil trees, particularly for mid and old cambial ages (Fig. 4a). This is probably due to the fact that only a few subfossils were sampled near the base of their former trees. The biases of the Subfossil_RCS variant constructed under the S2_H440 scenario are less pronounced and only the last 30-35 years are negatively distorted because at this height the growth of living trees is more similar to the average growth of all subfossil trees (Figs 2c and 4).

Using the S2_Hmix subset, all RCS variants (HSpecific_RCS, HSpecific_SF-RCS or Subfossil_RCS) show important and similar biases due to sampling height. More precisely, RCS indices for the first part of the 20th century are positively distorted, whereas the last 30-35 years are negatively distorted relative to the unbiased HSpecific_RCS variants of the S2_H80 and S2_H440 scenarios. This situation reflects the fact that whatever the sampling height, the final portion of individual series from living trees are systematically negatively biased (Fig. 4b, c). Consequently, although the mixing of all sampling heights on living trees produces a growth curve very similar to the average of all subfossil stems, this scenario cannot be used to produce a RCS chronology free of bias due to sampling heights.

Developing RCS chronologies not biased by sampling height 
The above analyses indicate that sampling heights must be considered when developing long RCS chronologies built with samples coming from variable or unknown heights on trunks. Achieving high replication and regular temporal distribution of samples (i.e., a stable mean cambial age) and replicating chronologies would help obtain low mean biases in the subfossil portion of these chronologies (Fig. 6d-e). However, correcting biases in the final, living portion is more problematic. These biases result from the changing representation of sampling heights in the dataset (generally from unknown and variable heights in subfossils to known and constant height in living trees), along with alignment of living trees by their negatively biased ends (Fig. 4c). A possible solution would be to sample living trees at the less biased height (around $440 \mathrm{~cm}$ in our case; this assumes that a detailed stems analysis has been performed), and selecting the right combination of series of different lengths (i.e., young and old trees) so as to generate a negligible mean bias at the chronology end (Supplementary Fig. 3). However, obtaining the right combination of series of different lengths may be difficult in the field because series starting years are unknown before sampling and appropriate trees may not be available. An alternative approach would consist of standardizing living trees in a height-specific manner apart from subfossil samples by sampling all trees at a consistent height and using their growth curve to implement the RCS method (Gennaretti et al. 2014c). This split-subset approach has been previously used when combining living trees with historic or subfossil trees in various contexts (Büntgen et al., 2010, 2011; Stambaugh et al., 2011). Although, the split-subset approach will remove bias due to sampling heigths in living trees (Fig. 5), it is based on the assumption that living and subfossil specimens grew under similar climate conditions. If this assuption is incorrect, the approach would attenuate low frequencies in the living part of the chronology relative to the much longer subfossil portion. Furthermore, the split-subset approach would not ensure that biaises due to sampling heigths cancel among subfossil samples during time periods 
of unstable age structure and additionnal approaches or data treatments need to be developped to minimize biaises.

Consequently, using the highly replicated L20 dataset as an example (586 subfossil specimens along with 25 living trees sampled at $400 \mathrm{~cm}$; Gennaretti et al., 2014c), we developed a correction procedure (hereafter referred to as the "pivot correction") that allowed all samples to be standardized together. First, all series were processed according to the typical RCS approach (dividing each series by the overall growth curve), thus generating a height-specific bias into each standardized series (see Fig. 4b). Second, we applied a height-independent correction procedure to each individual series, based on similarities among height-specific biases curves, in order to remove biases introduced during the first step. Most bias curves display a regular increase towards their maximum value, followed by a regular decrease (Fig. 4c). In addition, slopes of both the increasing and decreasing trends are similar among sampling heights with the exception of heights of less than one meter, which diverge somewhat from this pattern. Accordingly, the pivot correction consisted of: 1- smoothing all RCS-standardized series from the L20 dataset and aligning all smoothed series by their respective maximum RCS index; 2- computing the mean slope preceding this maximum by regressing against time all corresponding observations from all series (Supplementary Fig. 4a); 3- similarly, computing the mean slope following the maximum (Supplementary Fig. 4b); 4- pivoting separately the grouped pre- and post-maximum unsmoothed sub-series by subtracting the fitted regression values, thus using the maximum value as the pivot; 5- determining the youngest cambial age corresponding to the minimum median bias (i.e. median index $\sim 1$ ) and to a low spread among individual indexed series (i.e., low interquartile range) before the series was pivoted (e.g., for L20 series, we selected cambial age 43); 6- conducting a 
translation on each corrected series so as to make the value of the selected cambial age equal to its pre-rotation value; and 7- averaging all corrected series according to calendar years. Steps 5 and 6 are necessary because step 4 results in series with a stationary average bias equal to the preceding maximum value (see Fig. 4b), which is height-dependent and thus unknown and variable, at least in the subfossil portion of the chronology. Consequently, pivoted series must be translated using a common characteristic in order to minimize difference of mean bias among series. For example, in Fig. 4b, cambial ages around 20 years are characterized by low and similar biases for most sampling heights.

Results of the pivot correction at L20 (Fig. 8a) were compared to its uncorrected variant, as well as with the split-subset variant developed by Gennaretti et al. (2014c) and a signal-free RCS computed with the standard options of the software CRUST (Melvin \& Briffa 2014). First, all chronologies are very similar before the $19^{\text {th }}$ century, indicating that the pivot correction did not distort low frequencies trends and that the correction is unimportant when heights are mixed. Second, the pivot anomaly relative to the uncorrected variant is correlated $(r=0.75)$ to the mean cambial age along the chronology and this trend mirrors the correlation $(\mathrm{r}=-0.62)$ between mean cambial age and simulated biases in the S1_400 scenario (Supplementary Fig. 5). These inverse correlations suggest that the pivot correction is adequately compensating for RCS bias induced by the varying age structure in the L20 dataset. In contrast, the signal-free RCS chronology is very similar to the uncorrected chronology because the signal-free procedure does not account for varying sampling heights. Consequently, the pivot correction produce a chronology that is systematically above its uncorrected, split-subset and signal-free variants over the recent time periods (1780-1870 and 1930-2010) of unstable mean cambial age, also corresponding to the 
progressive alignment of living trees by their negatively biased final year (Fig. 8a). The uncorrected and signal-free chronologies are especially negative relative to the other ones. To further confirm that these recent differences between the corrected and uncorrected series are not artefacts of the method, we applied the pivot correction to the ensemble of ring width series from the varying sampling heights of our 15 living trees and compared them to the median of series processed with the RCS method in a height-specific manner, which are though to be unbiased by varying sampling heights (see Fig. 5). Contrary to the standard RCS approach (i.e. the S2_Hmix series in Supplementary Fig 6), the low-frequency signals of the corrected chronology display no long-term trend relative to the median of the height-specific RCS chronologies. This suggests that the pivot correction is efficient in removing biases caused by RCS standardization at the recent chronology end.

The pivot correction differs from previous adjustments of the RCS method. Most of these adjustments were designed to improve the fit of the age-growth model to each individual treering series when the collection of samples is thought to be heterogeneous, due for example to variable microsite conditions (Biondi and Qeadan, 2008; Nicault et al., 2010; Yang et al., 2011; Björklund et al., 2013; Matskovsky and Helama, 2014) or to generate an age-growth model not distorted by the climate signal (Melvin and Briffa, 2014). Instead, the pivot correction is intended to remove biases due to heterogeneous sampling heights and thus can be used to complement other correction procedures. Its main advantage is that all tree ring series are processed in the same height-independent manner. For this reason, recent as well as past biases due to sampling height can be attenuated even if sampling heights are unknown. Its main limitations are the same as the typical RCS method (i.e. high replications of trees and homogeneous populations not 
disturbed by external non-climatic factors). In addition, a detailed stems analysis on living trees must confirm that growth curves are height-specific and that the height-specific biases curves share the similarities discussed in the previous section. The pivot correction has been specifically developed for eastern Canadian lakeshore black spruce trees and its applicability to other species and contexts is not certain.

\section{Conclusion:}

In this study we have shown that the sampling height of trees is an important issue to consider when developing RCS tree ring chronologies in situations where sampling height is unknown or variable among samples. Not accounting for this factor can potentially introduce large biases in the final portion of RCS chronologies, as well as during time periods of changing age structure. These biases may lead to erroneous reconstructions of recent climatic trends and cause false divergence between tree ring and climate series.

Our study shows that the assumption of growth trend stability with tree height has to be tested when heights on trunks are unknown or mixed among samples. There is no indication that other conifer species are not influenced by this problem. Of course, the importance of this issue would be species and context-specific and would depend on several factors, such as the shape and variability of the growth curves along trunks, the variability of sampling heights among samples, and the temporal variability of sample replication and mean cambial age. 
The split-subset approach, which consists of separately standardizing heterogeneous data subsets, is a conservative approach that may be useful to attenuate biases caused by varying sampling heights in trunks. This approach would be robust in situations where past and recent sample subsets have grown in similar climate conditions and display a stable age structure. However, past climate conditions are generally unknown (they are the target of tree ring reconstructions) and the mean cambial age is unstable in most tree ring chronologies, thus more robust correction procedures may be needed. In this study, a detailed analysis of the influence of sampling heights on the age-related grow curve and associated biases in RCS chronologies enabled us to develop a correction that appears robust in the context of our study (lakeshore black spruce forests of the eastern Canadian taiga).

\section{Acknowledgements:}

The authors wish to thank Pierre-Paul Dion for field assistance and Étienne Boucher and two reviewers for constructive comments on a previous version of this paper. This research is a contribution of the ARCHIVES project and was financially supported by NSERC, HydroQuebec, Ouranos, ArcticNet, and the Centre d'études nordiques (CEN).

\section{References:}

Alteyrac, J., Zhang, S., Cloutier, A., Ruel, J.-C., 2005. Influence of stand density on ring width and wood density at different sampling heights in black spruce (Picea mariana (Mill.) BSP). Wood and Fiber Science, 37, 83-94. 
Alteyrac, J., Cloutier, A., Zhang, S.Y., 2006. Characterization of juvenile wood to mature wood transition age in black spruce (Picea mariana (Mill.) B.S.P.) at different stand densities and sampling heights. Wood Science and Technology, 40, 124-138.

Arseneault, D., Dy, B., Gennaretti, F., Autin, J., Bégin, Y., 2013. Developing millennial tree ring chronologies in the fire-prone North American boreal forest. Journal of Quaternary Science, 28, 283-292.

Biondi, F., Qeadan, F., 2008. A theory-driven approach to tree-ring standardization: defining the biological trend from expected basal area increment. Tree-Ring Research, 64, 81-96.

Björklund, J.A., Gunnarson, B.E., Krusic, P.J., Grudd, H., Josefsson, T., Östlund, L., Linderholm, H.W., 2013. Advances towards improved low-frequency tree-ring reconstructions, using an updated Pinus sylvestris L. MXD network from the Scandinavian Mountains. Theoretical and Applied Climatology, 113, 697-710.

Briffa, K.R., Jones, P.D., Bartholin, T.S., Eckstein, D., Schweingruber, F.H., Karlen, W., Zetterberg, P., Eronen, M., 1992. Fennoscandian summers from AD 500: temperature changes on short and long timescales. Climate Dynamics, 7, 111-119.

Briffa, K.R., Melvin, T.M., 2011. A closer look at regional curve standardization of tree-ring records: justification of the need, a warning of some pitfalls, and suggested improvements in its application, in: Hughes, M.K., Swetnam, T.W. \& Diaz, H.F. (Eds.), Dendroclimatology, Progress and Prospects. Springer, Dordrecht, pp. 113-145.

Büntgen, U., Frank, D.C., Schmidhalter, M., Neuwirth, B., Seifert, M., Esper, J., 2006. Growth/climate response shift in a long subalpine spruce chronology. Trees - Structure and Function, 20, 99-110. 
Büntgen, U., Esper, J., Frank, D.C., Nicolussi, K., Schmidhalter, M., 2005. A 1052-year tree-ring proxy for Alpine summer temperatures. Climate Dynamics 25: 141-153.

Büntgen, U., Tegel, W., Nicolussi, K., McCormick, M., Frank, D., Trouet, V., Kaplan, J. O., Herzig, F., Heussner, K.U., Wanner, H., Luterbacher, J., Esper, J., 2011. 2500 years of European climate variability and human susceptibility. Science, 331, 578-582.

Clyde, M.A., Titus, S.J., 1987. Radial and longitudinal variation in stem diameter increment of lodgepole pine, white spruce, and black spruce: species and crown class differences. Canadian Journal of Forest Research, 17, 1223-1227.

Cook, E.R., Briffa, K.R., Meko, D.M., Graybill, D.A., Funkhouser, G., 1995. The 'segment length curse' in long tree-ring chronology development for palaeoclimatic studies. Holocene 5, 229-237.

Cook, E.R., Buckley, B.M., Palmer, J.G., Fenwick, P., Peterson, M.J., Boswijk, G., Fowler, A., 2006. Millennia-long tree-ring records from Tasmania and New Zealand: A basis for modelling climate variability and forcing, past, present and future. Journal of Quaternary Science, 21, 689-699.

D'Arrigo, R., Wilson, R., Liepert, B., Cherubini, P., 2008. On the "Divergence Problem" in Northern Forests: A review of the tree-ring evidence and possible causes. Global and Planetary Change, 60, 289-305.

Eronen, M., Zetterberg, P., Briffa, K.R., Lindholm, M., Merilainen, J. \& Timonen, M., 2002. The supra-long Scots pine tree-ring record for Finnish Lapland: Part 1, chronology construction and initial inferences. Holocene, 12, 673-680. 
Esper, J., Cook, E.R., Krusic, P.J., Peters, K., Schweingruber, F.H., 2003. Tests of the RCS method for preserving low-frequency variability in long tree-ring chronologies. Tree-Ring Research, 59, 81-98.

Esper, J., Niederer, R., Bebi, P., Frank, D., 2008. Climate signal age effects-Evidence from young and old trees in the Swiss Engadin. Forest Ecology and Management, 255, 3783-3789.

Esper, J., Düthorn, E., Krusic, P.J., Timonen, M., Büntgen, U., 2014. Northern European summer temperature variations over the Common Era from integrated tree-ring density records. Journal of Quaternary Science, 29, 487-494.

Friedrich, M., Remmelel, S., Kromer, B., Hofmann, J., Spurk, M., Kaiser, K. F., Orcel, C., Kuppers, M., 2004. The 12,460-year Hohenheim oak and pine tree-ring chronology from central Europe - A unique annual record for radiocarbon calibration and paleoenvironment reconstructions. Radiocarbon, 46, 1111-1122.

Fritts, H. C., 1976. Tree Rings and Climate. Academic Press, London, New York and San Francisco.

Gennaretti, F., Arseneault, D., Bégin, Y., 2014a. Millennial stocks and fluxes of large woody debris in lakes of the North American taiga. Journal of Ecology, 102, 367-380.

Gennaretti, F., Arseneault, D., Bégin, Y., 2014b. Millennial disturbance-driven forest stand dynamics in the Eastern Canadian taiga reconstructed from subfossil logs Journal of Ecology, 102, 1612-1622.

Gennaretti, F., Arseneault, D., Nicault, A., Perreault, L., Bégin, Y., 2014c. Volcano-induced regime shifts in millennial tree-ring chronologies from northeastern North America. Proceedings of the National Academy of Sciences, 111, 10077-10082. 
Girardin, M.P., Guo, X.J., De Jong, R., Kinnard, C., Bernier, P., Raulier, F., 2014. Unusual forest growth decline in boreal North America covaries with the retreat of Arctic sea ice. Global Change Biology 20, 851-866.

Grudd, H., Briffa, K.R., Karlén, W., Bartholin, T.S., Jones, P.D. \& Kromer, B., 2002. A 7400year tree-ring chronology in northern Swedish Lapland: natural climatic variability expressed on annual to millennial timescales. Holocene 12, $657-665$.

Gunnarson, B.E., Linderholm, H.W., 2002. Low-frequency summer temperature variation in central Sweden since the tenth century inferred from tree rings. Holocene 12, 667-671.

Linderholm, H.W., Gunnarson, B.E., Liu, Y., 2010. Comparing Scots pine tree-ring proxies and detrending methods among sites in Jämtland, west-central Scandinavia. Dendrochronologia, 28, 239-249.

Matskovsky, V.V., Helama, S., 2014. Testing long-term summer temperature reconstruction based on maximum density chronologies obtained by reanalysis of tree-ring data sets from northernmost Sweden and Finland. Climate of the Past, 10, 1473-1487.

McCarroll, D., Loader, N.J., Jalkanen, R., Gagen, M.H., Grudd, H., Gunnarson, B.E., Kirchhefer, A.J., Friedrich, M., Linderholm, H.W., Lindholm, M., Boettger, T., Los, S.O., Remmele, S., Kononov, Y.M., Yamazaki, Y.H., Young, G.H.F., Zorita, E., 2013. A 1200-year multiproxy record of tree growth and summer temperature at the northern pine forest limit of Europe. Holocene, 23, 471-484.

Melvin, T.M., Briffa, K.R., 2008. A "signal-free" approach to dendroclimatic standardisation. Dendrochronologia, 26, 71-86.

Melvin, T.M., Briffa, K.R., 2014. CRUST: Software for the implementation of Regional Chronology Standardisation: Part 1. Signal-Free RCS. Dendrochronologia, 32, 7-20. 
Melvin, T.M., Brifffa, K.R., Nicolussi, K., Grabner, M., 2007. Time-varying-response smoothing. Dendrochronologia, 25, 65-69.

Nicault, A., Guiot, J., Edouard, J.L., Brewer, S., 2010. Preserving long-term fluctuations in standardisation of tree-ring series by the adaptative regional growth curve (ARGC). Dendrochronologia, 28, 1-12.

PAGES 2k Consortium, 2013. Continental-scale temperature variability during the past two millennia. Nature Geoscience, 6, 339-346.

Park, Y.-I., Koubaa, A., Brais, S., Mazerolle, M.J., 2009. Effects of cambial age and stem height on wood density and growth of jack pine grown in boreal stands. Wood and Fiber Science, 41, 346-358.

Peters, R.L., Groenendijk, P., Vlam, M., Zuidema, P.A., 2015. Detecting long-term growth trends using tree rings: a critical evaluation of methods. Global Change Biology, 21, 2040-2054.

Porter, T.J., Pisaric, M.F.J., 2011. Temperature-growth divergence in white spruce forests of Old Crow Flats, Yukon Territory, and adjacent regions of northwestern North America. Global Change Biology, 17, 3418-3430.

Rossi, S., Deslauriers, A., Anfodillo, T., Carrer, M., 2007. Age-dependent xylogenesis in timberline conifers. New Phytologist, 177, 199-208.

Rossi, S., Tremblay, M.-J., Morin, H., Levasseur, V., 2009. Stand structure and dynamics of Picea mariana on the northern border of the natural closed boreal forest in Quebec, Canada. Canadian Journal of Forest Research 39, 2307-2318.

Shao, X., Wang, S., Zhu, H., Xu, Y., Liang, E., Yin, Z. Y., Xu, X., Xiao, Y., 2009. A 3585-year ring-width dating chronology of Qilian juniper from the northeastern Qinghai-Tibetan Plateau. IAWA Journal, 30, 379-394. 
Stambaugh, M.C., Guyette, R.P., McMurry, E.R., Cook, E.R., Meko, D.M., Lupo, A.R., 2011. Drought duration and frequency in the U.S. Corn Belt during the last millennium (AD 992-2004). Agricultural and Forest Meteorology, 151, 154-162.

Yang, B., Sonechkin, D.M., Datsenko, N.M., Ivashchenko, N.N., Liu, J., Qin, C., 2011. Eigen analysis of tree-ring records: Part 1, a limited representativeness of regional curve. Theoretical and Applied Climatology, 106, 489-497. 
Table 1: Meaning of technical terms frequently used in this study

\begin{tabular}{|c|c|}
\hline Term & Definition \\
\hline Growth curve & $\begin{array}{l}\text { Mean smoothed growth of a homogeneous group of samples aligned } \\
\text { according to cambial age. }\end{array}$ \\
\hline Smoothed series & $\begin{array}{l}\text { Series smoothed with a cubic spline with a } 50 \% \text { frequency cutoff and a time- } \\
\text { varying response starting at } 10 \text { years and increasing by one each year (Melvin } \\
\text { et al., 2007). }\end{array}$ \\
\hline Age structure & $\begin{array}{l}\text { Frequency distribution of cambial ages of all trees corresponding to a given } \\
\text { calendar year of a chronology. }\end{array}$ \\
\hline Bias & $\begin{array}{l}\text { A systematic average error specific to each cambial age due to sampling } \\
\text { height when processing tree ring series with the RCS method. }\end{array}$ \\
\hline S1_H80 & $\begin{array}{l}\text { A simulation scenario developed to examine RCS biases in a millennial tree } \\
\text { ring chronology comprising subfossil stems sampled at random heights and } \\
\text { living stems sampled at } 80 \mathrm{~cm} \text { above the soil surface }\end{array}$ \\
\hline S1_H400 & An alternative scenario to $\mathrm{S} 1 \_\mathrm{H} 80$ with living trees sampled at $440 \mathrm{~cm}$. \\
\hline S2_H80 & $\begin{array}{l}\text { Analysis of RCS biases in real living trees sampled at } 80 \mathrm{~cm} \text {. Three RCS } \\
\text { variants were considered (see below) }\end{array}$ \\
\hline $\mathrm{S} 2 \_\mathrm{H} 440$ & Same as for S2_H80, but with living trees sampled at $440 \mathrm{~cm}$. \\
\hline S2_Hmix & $\begin{array}{l}\text { Same as for } \mathrm{S}_{2} \mathrm{H} 80 \text { and } \mathrm{S} 2 \mathrm{H} 440 \text {, but with living trees sampled every } 40 \mathrm{~cm} \\
\text { from } 0 \mathrm{~cm} \text { to } 1080 \mathrm{~cm} \text {. }\end{array}$ \\
\hline HSpecific_RCS & $\begin{array}{l}\text { A RCS variant (applied to the three "S2" scenarios above), in which tree ring } \\
\text { series are RCS-standardized using their corresponding height specific growth } \\
\text { curve (either } 80 \mathrm{~cm}, 440 \mathrm{~cm} \text { or all heights mixed) }\end{array}$ \\
\hline HSpecific_SF-RCS & $\begin{array}{l}\text { Same as HSpecific_RCS, but using the Signal Free approach of Melvin and } \\
\text { Briffa (2008). }\end{array}$ \\
\hline Subfossil_RCS & $\begin{array}{l}\text { Same as HSpecific_RCS and HSpecific_SF-RCS but using the mean growth } \\
\text { curve of all subfossil stems sampled at our three sites }\end{array}$ \\
\hline
\end{tabular}




\section{Figure Legends:}

Fig. 1: Location of the three studied lakes in the taiga of Quebec with photographs showing their old-growth lakeshore forests and abrupt forest-lake transitions.

Fig. 2: Cartography of growth patterns according to sampling height. (a) Average growth patterns of 15 living trees sampled at three sites. Only pixels represented by three or more values in at least two sites are shown. The corresponding height-specific mean growth curves are illustrated in the Supplementary Fig. 1. (b) Significant differences among sites verified with a KruskalWallis one-way analysis of variance test. (c) Results of the Wilcoxon rank-sum test used to verify significant differences between growth patterns of living and subfossil $(\mathrm{N}=991)$ trees sampled at the same sites. The horizontal line shows the height of $440 \mathrm{~cm}$.

Fig. 3: Comparison of the growth curves between living and subfossil trees. For living trees we considered either the height at $440 \mathrm{~cm}$ (blue line) or all sampled heights mixed together (black). (a) Results of the Wilcoxon rank-sum tests used to verify significant differences (red color; $\mathrm{p}<0.1)$ between growth patterns of living and subfossil trees. The average growth curves (smoothed and unsmoothed) of living and subfossil trees (b) and their sample replication (c; logarithmic y-axis) are also shown. Only portions with sample replication greater than 2 are shown.

Fig. 4: Fig. 4. Age-related growth curves and associated biases according to sampling height. (a) Smoothed average growth curves of 15 living trees according to sampling height, along with the 
mean growth curve of the 991 subfossil trees sampled at the three sites. (b) Average bias that a tree ring series of a living tree would introduce in a RCS chronology according to sampling height and cambial age. For each sampling height, biases are calculated by dividing the growth curve of living trees by the growth curve of all subfossil trees. Only cambial ages with sample replication of at least 3 are shown for each curve. (c) Same as (b) after realigning the curves according to calendar years.

Fig. 5: Standardized tree growth according to stem height. (a) Cartography of tree growth after removing the height-specific age-related growth trends using the RCS method. (b) RCS chronologies for all heights. Only portions with sample replication greater than 2 are shown.

Fig. 6: Bias due to sampling height in millennial-long RCS tree ring chronologies simulated according to the S1_H80 and S1_H400 scenarios. (a) Bias curve generated from samples of each subfossil (black) and living (sampled at $80 \mathrm{~cm}$; red) tree after RCS standardisation using the growth curve of all subfossil trees. (b) same as (a) except that living trees (red) correspond to a sampling height of $400 \mathrm{~cm}$. Live period and length of individual series have been selected according to the scenarios illustrated in Supplementary Fig. 1 with corresponding bias curves from Fig 4b. The number of series available each year (c), the mean cambial age (d), and the mean RCS bias averaged from all individual series (e) are also shown for the S1_H80 and S1_H400 scenarios. Doubling the recruitment rate of subfossil trees between years 400-500 (dark gray bar) also disturbed the mean cambial age and entered into the mean RCS bias over the 200400 time period (light gray bar). 
Fig. 7: Effect of sampling height on the recent end of standardized tree ring chronologies using three data subset scenarios and three variants of the RCS method. The S2_H80, S2_H440, and S2_Hmix subsets refer to the samples taken at $80 \mathrm{~cm}(\mathrm{n}=15), 440 \mathrm{~cm}(\mathrm{n}=15)$, and at all sampling heights (n=332), respectively. The "HSpecific_RCS", HSpecific_SF-RCS" and Subfossils_RCS" variants correspond to the typical RCS method, the signal free RCS approach, and the typical RCS method with a subfossil-dominated dataset, respectively (See Table 1). In the first two variants, the standardization is relative to the average growth curve of the corresponding samples, while in the last variant, the standardization is relative to the average growth curve of subfossil stems.

Fig. 8: Comparison of correction procedures for RCS chronologies built with subfossil and living black spruce trees sampled at the L20 site. (a) The uncorrected RCS chronology is compared with its signal-free RCS and split-subset (Gennaretti et al., 2014c) variants, as well as its pivot correction variant developed here. Note than the uncorrected and signal-free RCS chronologies almost completely overlap. (b) Anomalies relative to the uncorrected RCS chronology for the three corrections are compared with the mean cambial age of the sampled trees. 

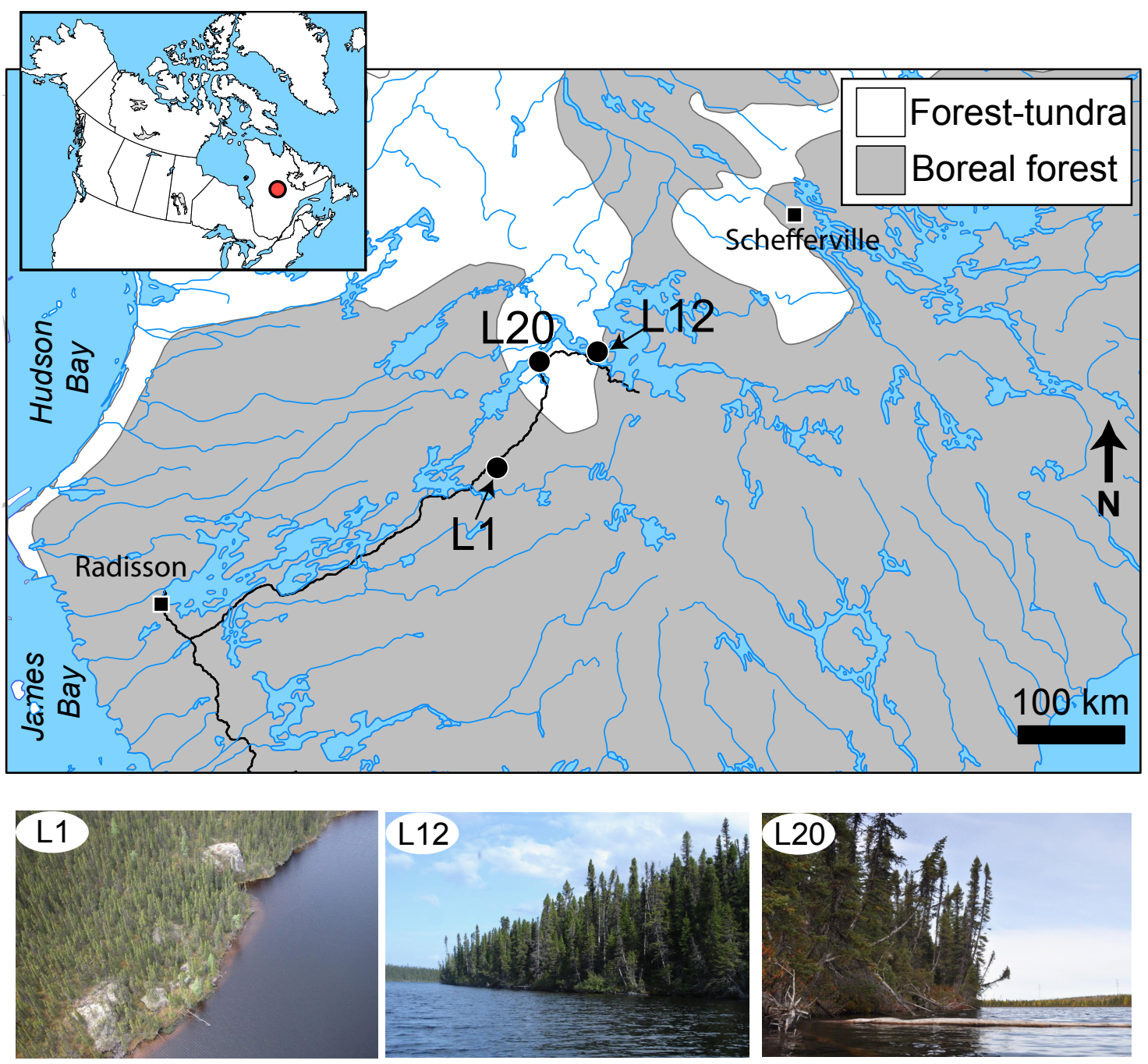


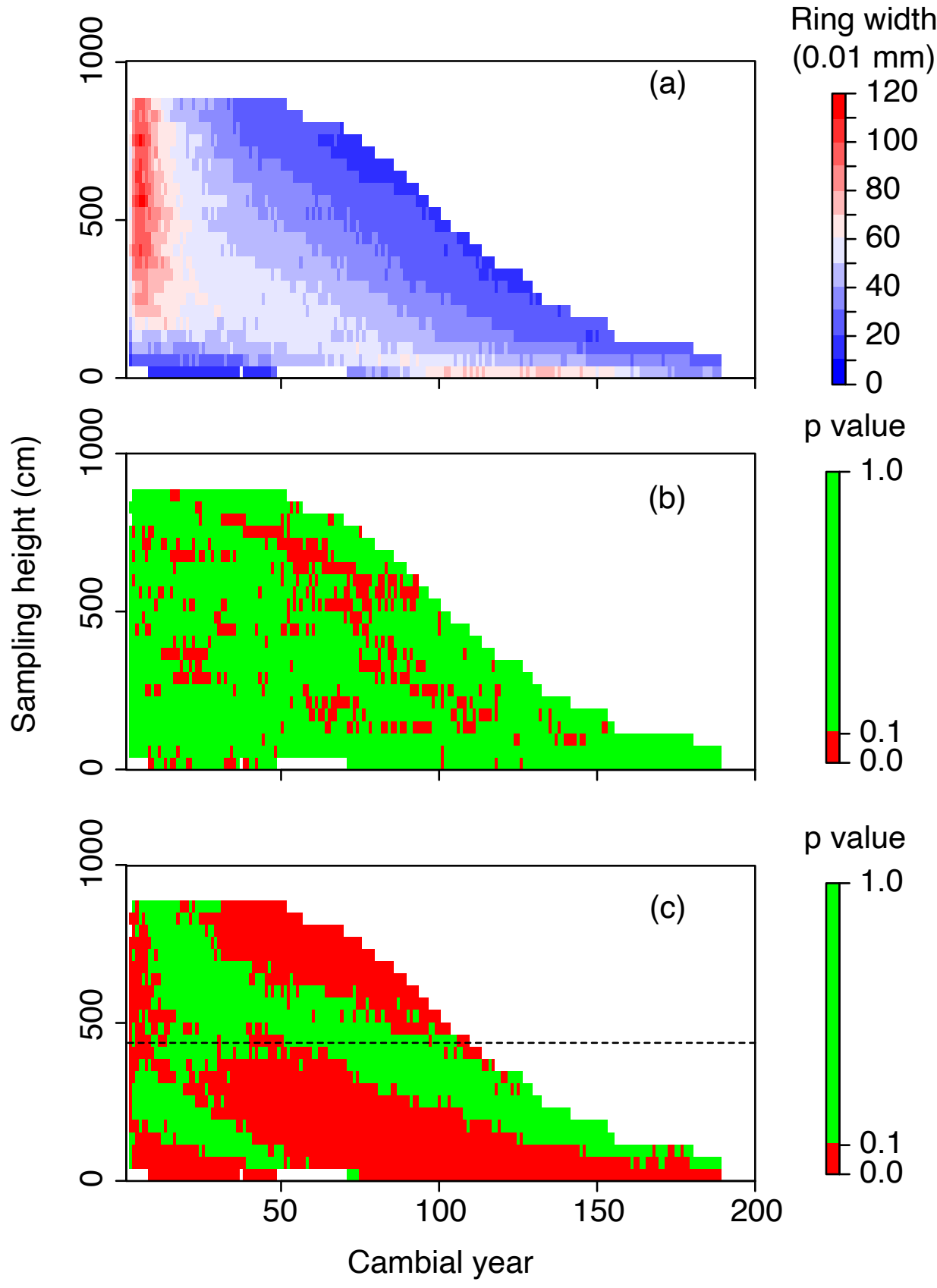



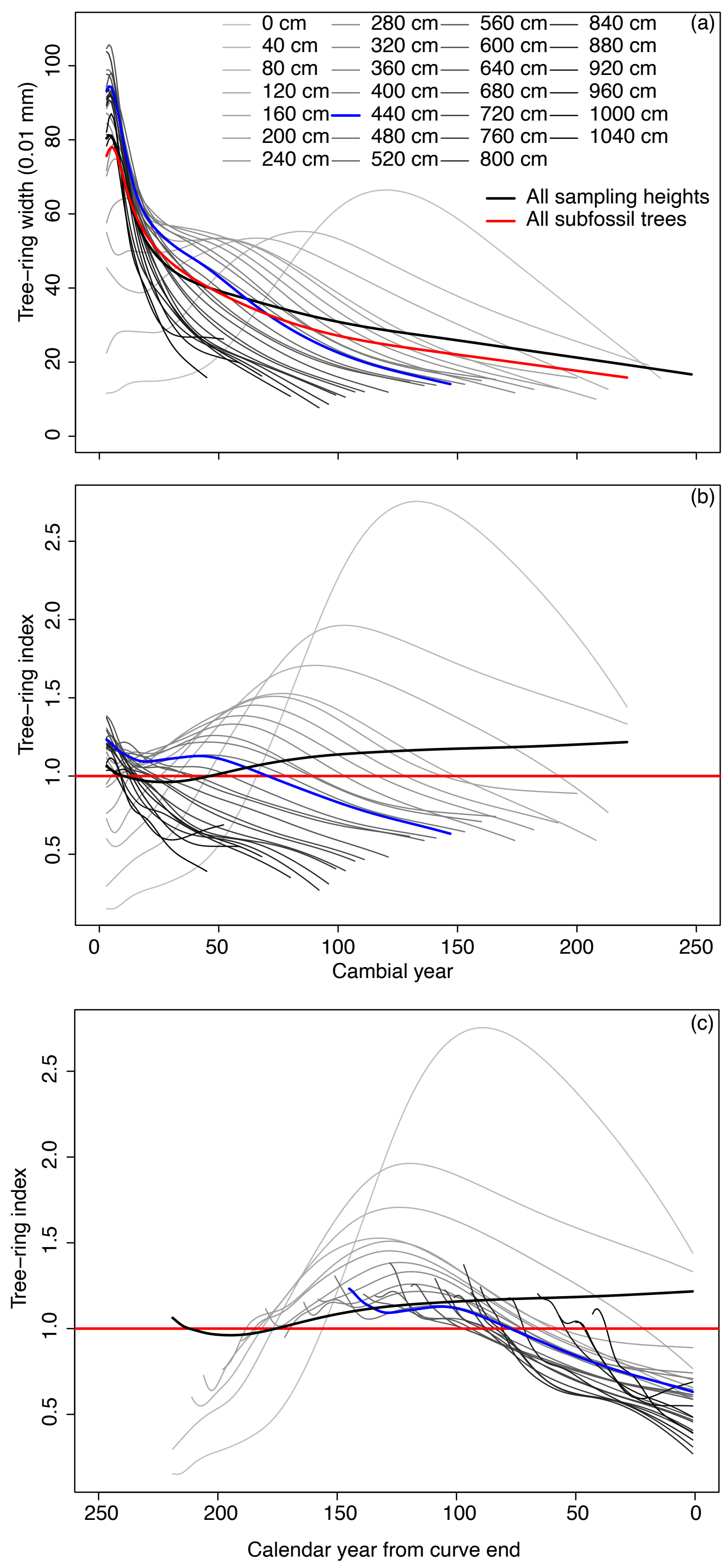

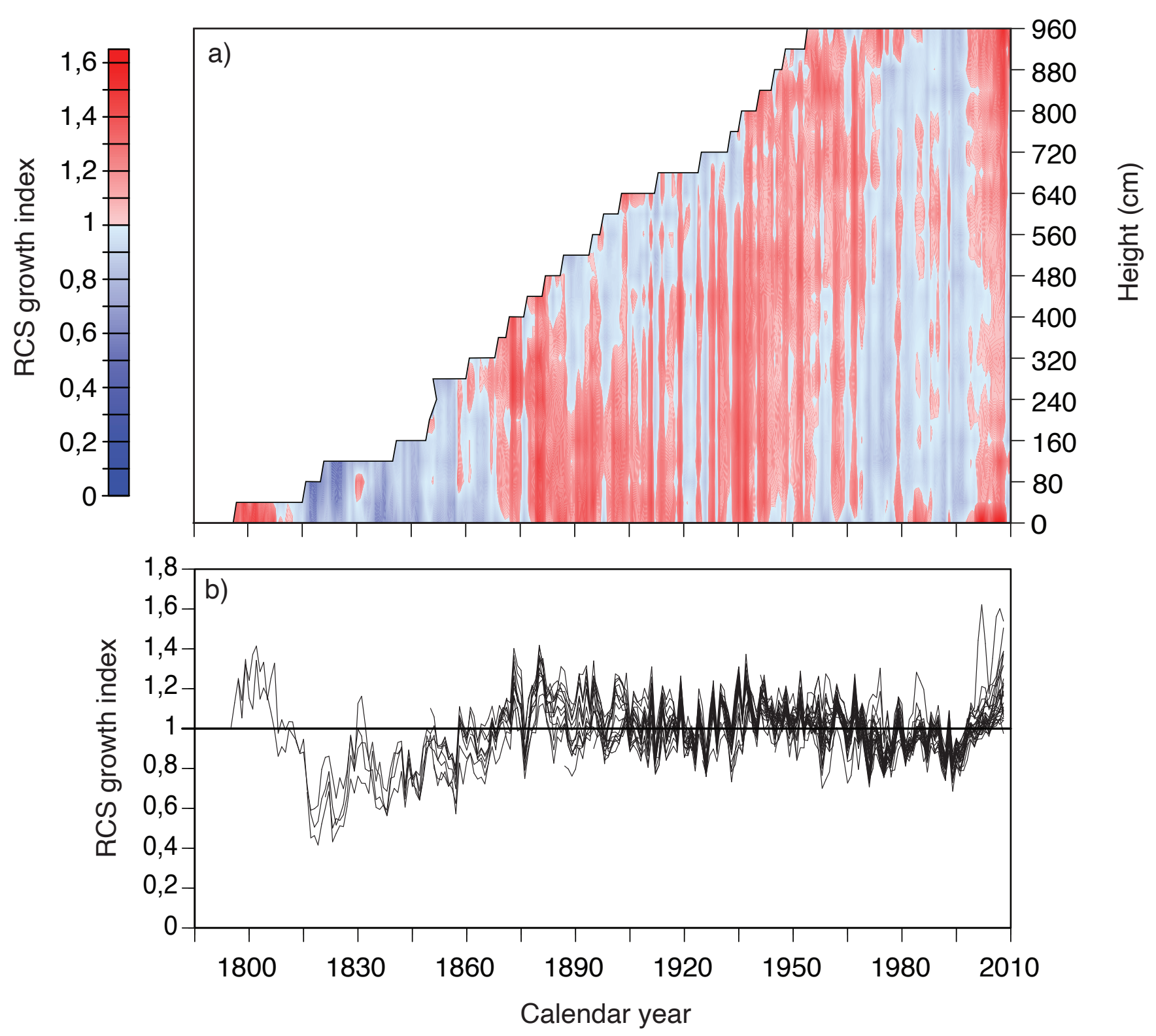

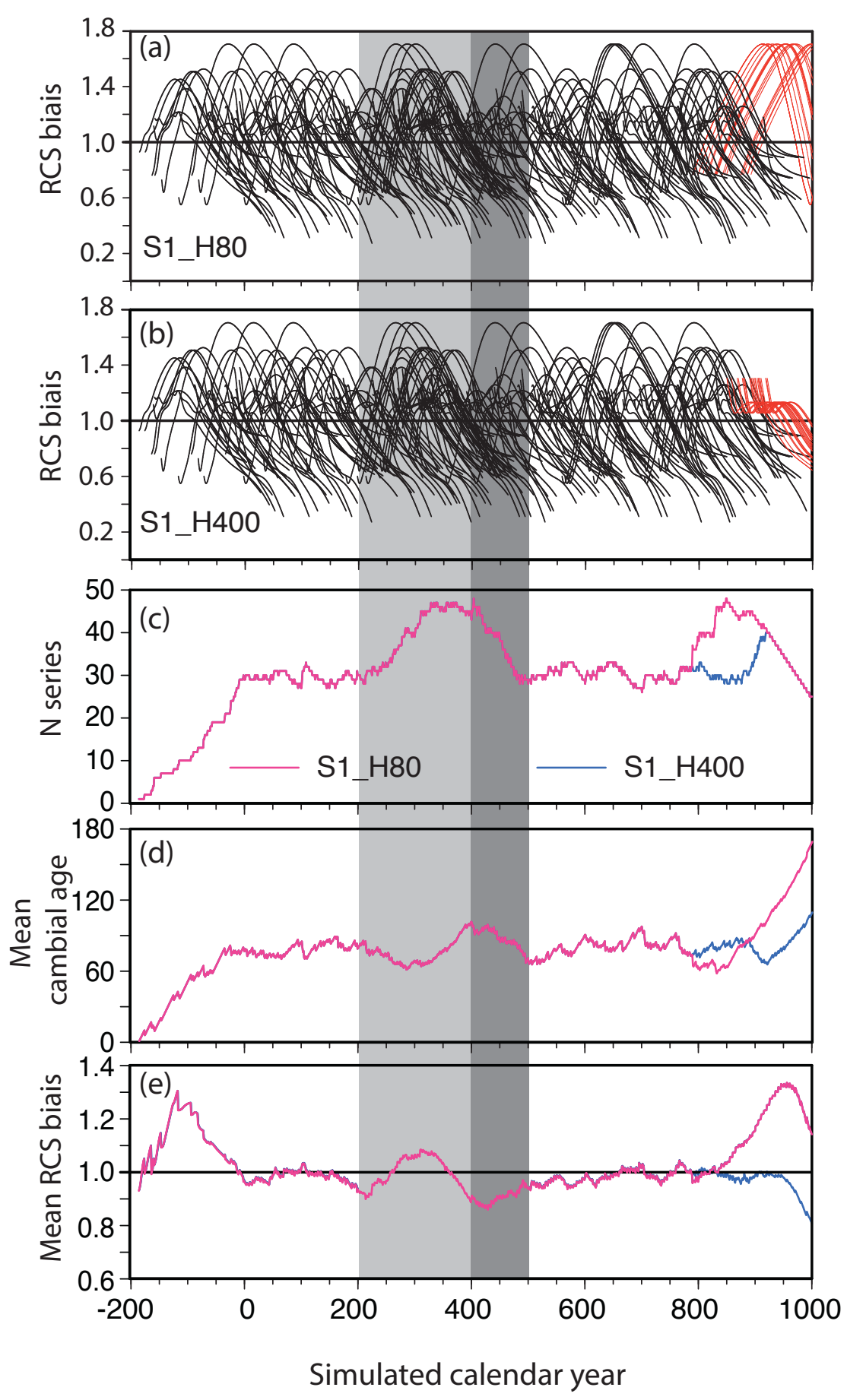


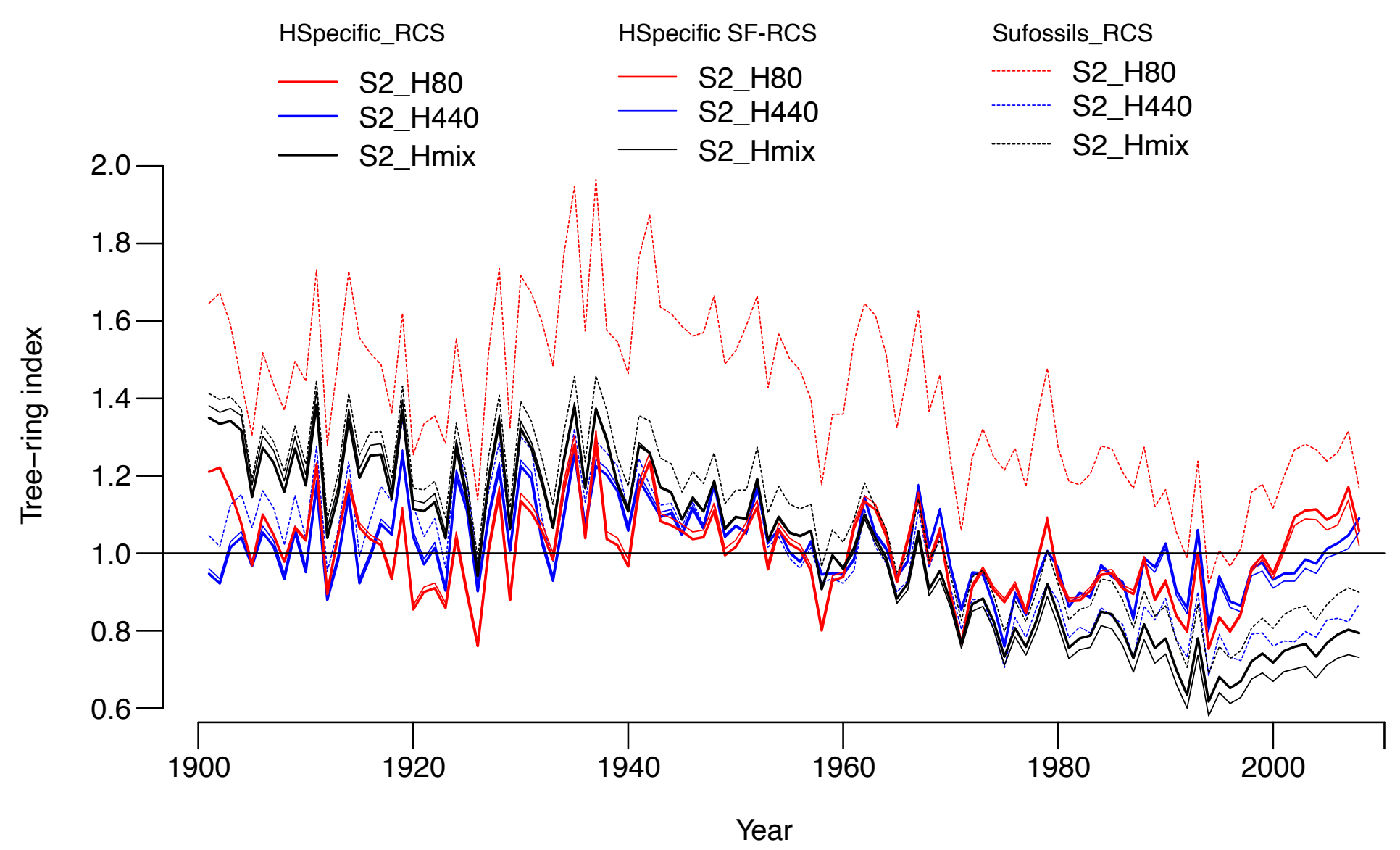



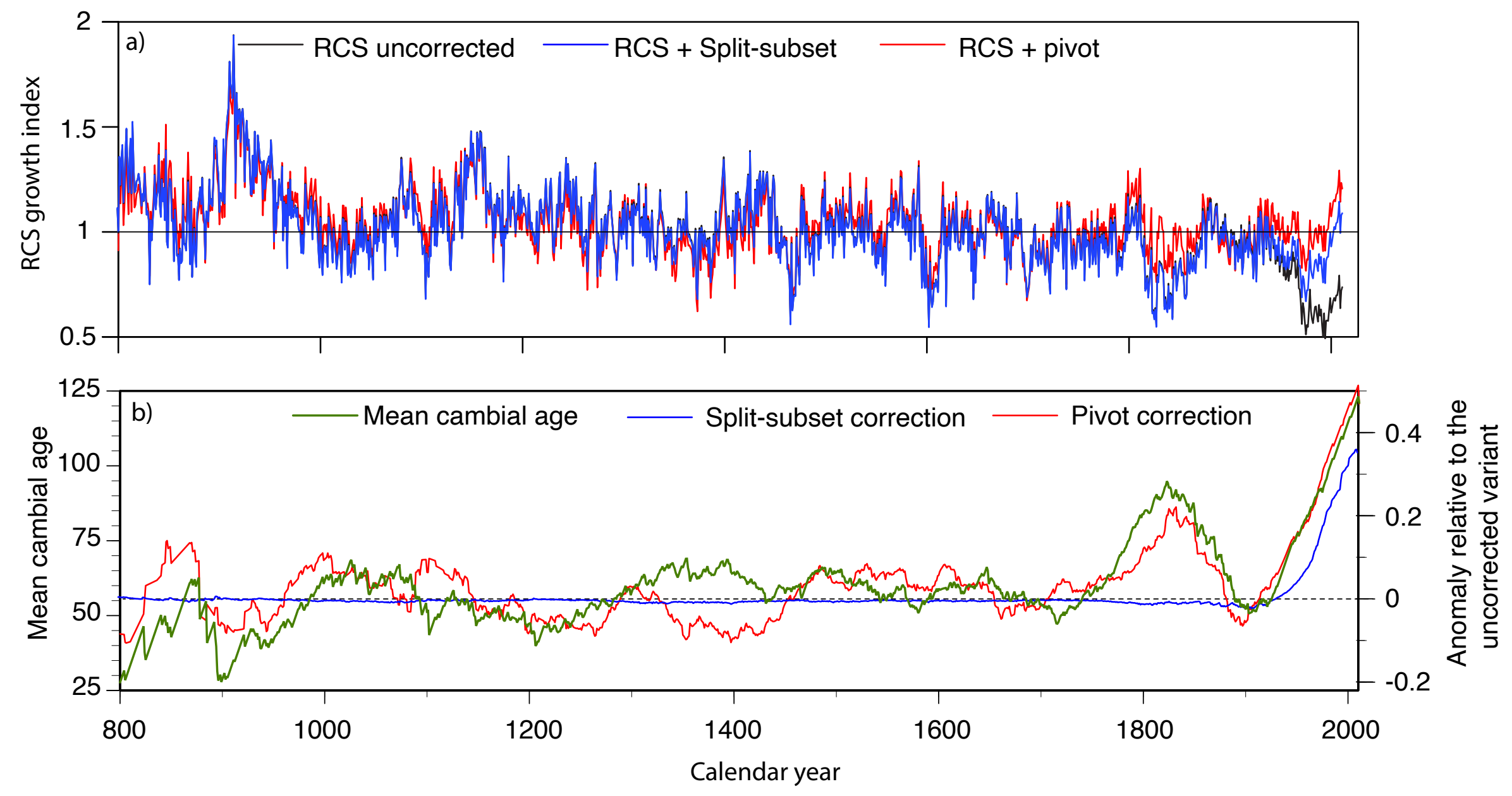